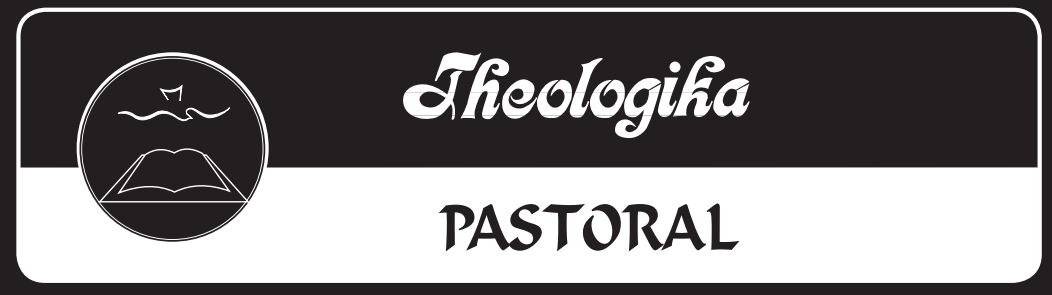

\title{
Los pastores adventistas: su rol y su formación teológica
}




\section{Ekkehardt Mueller}

Instituto de Investigación Adventista Washington - D.C. USA 


\section{RESUMEN}

"Pastores adventistas: su rol y su formación teológica" - El autor destaca la relevancia e importancia de la tarea pastoral, la cual requiere una amplia variedad de habilidades. Establece que esta tarea no solo es la más importante y gratificante, sino que sus resultados pueden ser visibles e invisibles y que en realidad los resultados de ella durarán por la eternidad. Señala sobre todo que esta tarea requiere de un entrenamiento teológico debido, meticuloso y, todo, responsable e inspirador. El autor centra sus apreciaciones y búsqueda en las epístolas paulinas pastorales a Timoteo y Tito y hace de ellas el reflejo de la tarea pastoral y la necesidad del debido entrenamiento. Con esto él concluye que tal como la iglesia es esencial, lo es también el ministerio pastoral que cuida de ella, ya que ambos se pertenecen y ambos se dan forma. Además, la gratitud por el don del ministerio debe reflejar el apoyarlo y fortalecerlo, de modo que este sea una constante bendición para la iglesia y la sociedad.

Palabras claves: Pastorado, ministerio, teología, formación, epístolas pastorales.

\section{SUMMARY}

“Adventist Pastors: Their Role and Their Theological Training" - The author stresses the relevance and importance of the ministerial task which requires a wide variety of skills. He stablishes that this job is not only the most meaningful and gratifying but also its results can be visible and invisibles and the results of it will endure for eternity. He shows that this task requires a correct and detailed theological training and over all responsible and inspiring one. The author centers his appreciations and research in the Pauline pastoral letters to Timothy and Titus and takes from them the diversity shown in pastoral job and the necessity of a correct training. With this, he concludes that as the church is essential, it is also the pastoral ministry that cares for it as they both belong and both shape each other. Besides, the gratitude for the gift of the ministry must reflect the support it and strengthen it in such a way that the ministry can be a constant blessing to the church and society.

Key words: Pastorate, ministry, theology, formation, pastoral epistles. 


\section{LOS PASTORES ADVENTISTAS: SU ROL Y SU FORMACIÓN TEOLÓGICA}

\section{INTRODUCCIÓN}

Uno de los trabajos más desafiantes es el ministerio pastoral. Los pastores son generalistas, "personas del renacimiento", cuyo llamado "requiere una amplia variedad de habilidades". ${ }^{1}$ Por un lado ellos tienen que domar "la tiranía de lo demasiado", ${ }^{2}$ y por el otro lado, tienen que aprender a vivir con el sentimiento frustrante de no haber logrado nada o, al menos, no tanto: las tensiones no han sido resueltas; la reconciliación no ha sucedido; los sermones no han sido capaces de motivar a la iglesia para enrolarse en el programa misionero; a pesar del consejo pastoral, algunos miembros se divorciaron; algunos estudios bíblicos parecen no conducir a ningún lado; y los comités y las juntas de iglesia son simplemente un dolor de cabeza. Un carpintero o un plomero saben lo que han hecho al final de un día y mirar hacia atrás en su día de labor con un sentido de satisfacción,

${ }^{1}$ Paul Cedar, "The Unique Role of the Pastor", in Mastering the Pastor Role, editado por P. Cedar, K. Hughes, and B. Paterson (Portland: Multinoah Press, 1991), 17.

${ }^{2}$ H. Peter Swanson, "Taming the Tyranny of Too Much", Ministry, (April 3, 2008), 5-8. 
pero un pastor a menudo tiene muy poca gratificación y los resultados pueden no ser vistos inmediatamente.

Aunque el ministerio pastoral es desafiante, a la larga es una de las ocupaciones más gratificantes. Algunos resultados pueden ser vistos casi de inmediato. La mejor satisfacción es que esos resultados pueden durar por la eternidad. Por lo tanto, ser llamado a servir como un pastor es extremadamente significativo y gratificante. Puede también ser muy beneficioso para la vida espiritual de uno, puesto que mientras uno trate de servir con sinceridad de corazón y manteniendo siempre una relación vibrante con Dios, permitiéndole que le dé su poder mediante el Espíritu Santo, uno es traído constantemente de vuelta al Señor.

En este estudio trataremos de ver brevemente, en las epístolas pastorales, la lista de varios prerrequisitos para un ministerio pastoral exitoso, y luego nos volveremos al rol del pastor y al entrenamiento teológico.

\section{El Ministerio Pastoral en las Epístolas Pasto- rales}

El fundamento bíblico para el ministerio pastoral ha sido descrito extensamente en varias publicaciones. ${ }^{3}$ Nos limitaremos ahora a las Epístolas Pastorales, en las cuales Timoteo y Tito, compañeros de Pablo, son los receptores. En cierta medida Timoteo y Tito deben servir como modelos para los pastores adventistas, y ciertamente, a

${ }_{3}^{3}$ Para la Iglesia Adventista del Séptimo Día, ver, Klaus-J. van Treek, Biblische und historische Grundlagen für ein Verständnis der Rolle des Predigers in der Gemeinschaft der Siebenten-Tags-Adventisten, www.german. adventistleadership.org, November 2001. 
menudo durante los servicios de ordenación a menudo se leen pasajes de las cartas pastorales.

\section{1 Timoteo}

Resulta interesante notar que en las Epístolas Pastorales las calificaciones personales y las funciones están entretejidas. Por ejemplo en 1 Timoteo 4:11 encontramos las funciones en las cuales Timoteo es pedido que actúe. En 1 Timoteo 4:12 el ejemplo de Timoteo es enfatizado. En 1 Timoteo 4:13 somos llevados de vuelta con las funciones. Los textos que tratan acerca del ministerio de Timoteo pueden agruparse en cuatro categorías. El fundamento de su ministerio, las calificaciones para el ministerio, y las diferentes funciones pastorales. Las calificaciones para el ministerio pueden ser subdivididas en calificaciones observables y calificaciones íntimas. Es más, las calificaciones encontradas en 1 Timoteo están relacionadas al mismo individuo, así como su relación con Dios, los miembros de familia, la iglesia y la sociedad. Ellas están enfocadas en el vivir una vida ejemplar. Las calificaciones de los obispos han sido incluidas, porque se asume que ellas también deben ser aplicadas a Timoteo.

(1) El fundamento del ministerio

- La verdad $(2: 4 ; 3: 15 ; 4: 3)$

- La palabra de Dios (4:5), la palabra de fe (4:6)

- La sana doctrina/buena doctrina $(1: 10 ; 4: 6)$

(2) Las calificaciones de una vida ejemplar ${ }^{4}$

${ }^{4}$ En 1 Timoteo 1:16 el término "ejemplo" (upotupwsis) es usado. 
(a) Calificaciones observables

- Amor (1:5; 4:12; 6:11), pero no amor al dinero (6:10-11; 3:3)

- Estando fundados en la buena/sana doctrina/ enseñanza (1:10 4:6. 16); 6:3)

- Teniendo fe (sincera) $(1: 5,19 ; 4: 12 ; 6: 11)$

- Manteniendo buenas relaciones familiares $(3 ; 2,4)$

- Sobriedad. temperancia, dominio propio (3:2)

- Hospitalidad (3:2)

- Buena reputación entre los de afuera (3:7), siendo irreprensible y teniendo respetabilidad (3:2)

- Devoción (4;7-8; 6:11)

- Ejemplo en el hablar (4:12)

- Conducta ejemplar (4:12)

- Pureza (4:12)

- Buen uso del don recibido (4:14)

- Seguidor de la justicia (6:11)

- Ser perseverante (6:11)

- Ser apacible (6:11; 3:3)

(b) Calificaciones internas

- Una buena conciencia $(1: 5,19)$

- Pelea la buena batalla $(1: 18 ; 6: 12)$

Pablo era un ejemplo de la paciencia de Cristo. Él fue la clase de pecador, a quien Jesús vino a salvar. En Timoteo 4:12 Timoteo es llamado a ser un ejemplo (tupos). La quíntuple enumeración de calificaciones, siguiendo el término "ejemplo", señala hacia la importancia del concepto de ser un ejemplo. Además, algunas de las calificaciones también son encontradas en otros lugares -e.g., Tito 6:11- de manera que emerge un modelo que entrelaza. Los textos clave, en los cuales emerge un número de cualidades o calificaciones pastorales, son enumerados, por los dos versículos arriba mencionados, específicamente 4:12 y 6:11 (enumeración séxtuple). 
- Autodisciplina para el propósito de la bondad (4:7)

- Cuidando de sí mismo (4:16)

(3) Funciones pastorales

- Mandando (4:11; 6:17), oponiéndose a ciertas acciones (5:11)

- Enseñando (4:11, 13; 6:2)

- Lectura pública de la Escritura (4:13)

- Animando/exhortando (5:1-2; 6:2) y amonestando (5:20).

- Ordenando ancianos (5:22)

- Enfrentando el problema de la herejía y asumiendo una posición contra las falsas doctrinas y fábulas (1:3-4; 4:7; 6:20).

El problema afrontado en 1 Timoteo es la herejía. ¿Cómo se supone que Timoteo lo afrontará? Enseñando la sana doctrina - lo cual incluye un entendimiento claro de una buena Teología- y al establecerse como ejemplo. 1 Timoteo parece sugerir que todos estamos mal acostumbrados a hablar acerca de las funciones pastorales separadas de las calificaciones pastorales. El rol de los pastores puede incluir ambos, ejecutando ciertas funciones y viviendo una vida ejemplar.

Además, pareciera que 1 Timoteo recalca las calificaciones a un mayor rango del que lo hace con las funciones. Esto es también cierto cuando el autor se refiere a los ancianos y diáconos (3:1-13). Encontramos muy poco acerca de las tareas que deben realizar los obispos. Ellos deben ser capaces de enseñar y deben dirigir y cuidar de la iglesia $(3: 3,5)$. Pero incluso estas dos tareas son parte de las numerosas calificaciones de la lista de 1 Timoteo 3. 
En el capítulo 5:17 el gobierno y la labor en la palabra y enseñanza. La frase "trabajando en la palabra" se entiende mediante las muchas traducciones (versiones) como refiriéndose a la predicación. ${ }^{5} \mathrm{El}$ mismo cuadro emerge con los diáconos. Ellos realizan su "ministerio", pero no se nos dice para nada cuál es su ministerio. En vez de eso prevalecen las calificaciones de ellos.

Como lectores de 1 Timoteo conseguimos que las calificaciones para el ministerio pueden ser más importantes que las funciones del ministro. Además, las calificaciones para el ministro no son simplemente prerrequisitos para los candidatos ministeriales y estudiantes de teología que son evaluados a comienzos del ministerio. Timoteo no es un alumno interno que justamente iniciaba su ministerio, cuando Pablo le dirige esta carta a él. Él ya se ha iniciado y servido en diferentes contextos. Todavía, Pablo le recuerda las calificaciones para el ministerio.

Esto puede sugerir que los pastores tienen que evaluar a Timoteo periódicamente. Hay espacio para crecer. Esto puede sugerir que los seminarios adventistas, mientras estén estrenando a futuros pastores, deben enfatizar estas calificaciones durante el proceso de entrenamiento de un modo u otro. Esto puede sugerir además que, en los eventos de la educación continua para los pastores, debe haber espacio para recordar lo que son, y no simplemente lo que ellos hacen. Por tanto, en nuestra tarea educacional, debemos estar seguros de construir carácter y no simplemente impartir conocimiento, por más importante que sea este último. Cuando hablamos acerca del rol de pastor, debemos añadir la dimensión de una vida ejemplar.

${ }^{5}$ Ver, e.g., ESV, NASB, NIV, NRSV, RSV. 


\section{2 Timoteo}

2 Timoteo presenta un cuadro completamente diferente. El fundamento del ministerio es el mismo. Sin embargo, hay un mayor énfasis sobre la verdad y sobre la Escritura. Los textos clave, en los cuales las cualidades pastorales están enumeradas en: 2 Timoteo 2:22 (enumera cinco), 2:2425 (enumera cinco) y 3:10-11 (enumera nueve). Algunos términos son usados en ambos 1 Timoteo y 2 Timoteo. ${ }^{6}$

(1) El fundamento del ministerio

- palabras sanas / doctrina $(1: 13-14 ; 4: 3)$

- Palabra de verdad (2:15), verdad (2:18, 25; $3: 7-8 ; 4: 4)$

- La enseñanza apostólica (3:10)

- La Escritura inspirada, la cual es apta para la enseñanza, redargüir, corrección y para instruir en justicia (3:15-17)

(2) Calificaciones para el ministerio

- Fe (sincera) (1:5; 2:22; 3:10)

- Usando el don de uno (1:6)

- No siendo tímido o avergonzado (1:7-8)

- Disponibilidad para sufrir (1:8) y resistencia a las dificultades (2:3; 3:11-12; 4:5)

- Reteniendo la norma de las palabras buenas y guardándolas (1:13-14)

- Siendo fuerte espiritualmente (2:3)

- Acordándose de Jesucristo (2:8)

- Huyendo de las pasiones juveniles (2:22)

${ }^{6}$ E.g., amor, fe, mansedumbre y justicia. 
- Justicia (2:22)

- Amor (2:22; 3:10)

- Paz (2:22)

- No siendo contencioso (2:24)

- Amable (2:24)

- Sufrido (2:24) paciente (3:10; 4:2), y perseverante (3:10)

- Manso (2:25)

- Propósito (tal vez firmeza) (3:10)

- Sobriedad (4:5)

- Conducta santa (3:10)

(3) Funciones pastorales

- Confiando el mensaje a otros (una cadena de testigos (2:2)

- Redimiendo, encargando, advirtiendo a los miembros de iglesia (2:14)

- Usando con corrección la Palabra de verdad (2:15)

- Tratando la herejía (2:16-18, 23)

- Enseñanza (2:24; 4:2)

- Corrigiendo con mansedumbre (2;25), reprobando, reprendiendo, exhortando (4:2)

- Predicando (4:2)

- Haciendo la obra de evangelismo (4:5)

Las funciones pastorales son más elaboradas que en 1 Timoteo. El concepto de misión, y posiblemente el entrenamiento de los testigos, se encuentra en 1 Tim 2:2. La predicación fue atribuida a Pablo en 1 Timoteo 2:7 pero no directamente a Timoteo. Sin embargo, en 2 Timoteo lo es. Además, "haz la obra de evangelista" se encuentra en 2 Timoteo. 


\section{Tito}

Tito es más breve y menos elaborado. No encontramos tantas calificaciones de las funciones de Tito como encontramos en las dos cartas dirigidas a Timoteo. De nuevo las calificaciones sobrepasan en número a las funciones. Cuando los ancianos/obispos son presentados, las calificaciones son más enfatizadas que las funciones, las cuales son reducidas a "reteniendo la palabra fiel que está de acuerdo con la enseñanza (didajé), de modo que él (el anciano) sea capaz tanto de exhortar con sana doctrina (didaskalia) y refutar a aquellos que contradicen" (1:9).

Una cuádruple enumeración de calificaciones es encontrada en 1 Timoteo 2:7-8. En tanto que en 1 Timoteo 4:12 Timoteo fue llamado a ser un ejemplo (tupos), en Tito 2:7 Tito es desafiado a mostrarse a sí mismo como un ejemplo (tupos). Tito es el responsable de la iglesia en Creta. Él también tiene que tratar con herejes, y la iglesia necesita alguna estructura administrativa. Él es llamado a ser un ejemplo y a asumir las funciones encargadas a él. Aunque la lista de funciones tal como es hallada en Tito no es tan abarcante como lo son las listas combinadas de 1 y 2 Timoteo, básicamente son mencionadas las mismas funciones.

(1) Fundamento del ministerio

- Verdad $(1: 1,14)$

- La palabra fiel que está de acuerdo con la enseñanza (1:9)

- Sana doctrina $(1: 9 ; 2: 1,7,10)$

- La Palabra de Dios (2:5)

(2) Calificaciones para el ministerio

- Manteniendo buenas relaciones familiares (1:6) 
- Irreprensible (1:7)

- Autocontrol y justo $(1: 7,8)$

- Hospitalidad (1:8)

- Santidad (1:8)

- Haciendo buenas obras (2:7)

- Manteniendo la pureza de la doctrina (2:7)

- Seriedad (2:7)

- Palabra sana e irreprochable (2:8)

- Viviendo vidas equilibradas, justas y piadosas (2:12)

- Esperando y aguardando la esperanza bienaventurada (2:13

(3) Funciones pastorales

- Estableciendo ancianos (1:5)

- Tratando con herejes (1:11; 3:9-10) y reprendiéndoles severamente (1:13)

- Hablando lo que está conforme a la sana doctrina (2:1)

- Hablando, exhortando y reprobando con toda autoridad (2:15) y hablando confiadamente (3:8)

\section{Resumen}

Aunque este no es un estudio exhaustivo del ministerio en las Epístolas Pastorales, todavía podemos resumir y sacar algunas conclusiones. Al hacerlo reconocemos que los otros libros del Nuevo Testamento contienen valiosos conceptos que aquí no son considerados.

Las Epístolas Pastorales enfatizan el fundamento en el cual se basa el ministerio en términos fuertes. Ellos hablan acerca de la verdad, enseñanza/doctrina y la Palabra 
de Dios. Se asume que existe la verdad la cual difiere de la herejía. Timoteo y Tito son desafiados a defender la verdad y a estar arraigados en la enseñanza apostólica y en la Escritura7 ${ }^{7}$. El pluralismo pareciera no ser una opción en estas cartas novotestamentarias. En ellas se encuentra un fuerte elemento apologético. Es la Escritura que incluye la tradición apostólica tal como es preservada en el Nuevo Testamento la que forma la columna vertebral del ministerio de Timoteo, y es la Escritura - Antiguo y Nuevo Testamento- y solo la Escritura la que debe ser la me-

${ }^{7}$ En las Cartas Pastorales encontramos más bien un énfasis fuerte en la "sana doctrina". La palabra didaskalia, enseñar la doctrina, es usada quince veces en las Epístolas Pastorales. Cuatro veces en conexión con el adjetivo "buena" y una con el adjetivo kalos, bueno. Además, en 1 Timoteo 6:3 las buenas palabras del Señor Jesucristo y la doctrina correcta están vinculadas. El término Didajé se encuentra dos veces (2 Tim 2:2; Tito 1:9). El término logos, traducido como "palabra", "dicho" o "mensaje" es usado veinte veces en las Cartas Pastorales. Una vez es empleada para la proclamación de los maestros falsos (2 Tim 2:7). En todas las demás instancias el uso es positivo y se refiere a la predicación del mensaje (2 Tim 1:13; Tito 2:8), al evangelio (1 Tim 6:3; Tito 1:9), o a la Palabra de Dios (1 Tim 4:5; 2 Tim 2:9; Tito 2:5). En algunos casos no solo puede describir el mensaje, sino puede señalar al registro escrito de la Palabra de Dios, llamada Escritura (e.g., 1 Tim 1:15; 3:1; 4:9; 2 Tim 2:11, 15; Tito 3:8) o los Evangelios del Nuevo Testamento (e.g., 1 Tim 6:3 -las buenas palabras de nuestro Señor Jesucristo") que hoy son parte de la Escritura. Además del término logos, otras dos palabras son usadas la cuales son traducidas como "Escritura". En 1 Timoteo 5:18 el Antiguo Testamento es citado y tenido como normativo. Una declaración de Jesús es yuxtapuesto. Ambos son referidos como la Escritura. Según 2 Timoteo 3:15 "las Sagradas Escrituras (grammata) ... son capaces de hacerte sabio para la salvación por la fe en Cristo Jesús". De acuerdo con los dos siguientes versículos "Toda la Escritura (graphe) es inspirada por Dios y es útil para enseñar (didaskalia), para redargüir, para corregir, para enseñar en justicia; para que el hombre de Dios sea perfecto, enteramente preparado para toda buena obra". Cuando tenemos que refutar falsas enseñanzas, tenemos que hacerlo con la Escritura. La Escritura es inspirada y es la base para la doctrina/enseñanza. 
dida para cualquier ministerio pastoral. Tan importantes como son la ciencia y las humanidades, particularmente la sociología, la sicología y la antropología, ellas jamás pueden remplazar a la Escritura ni tampoco debieran ser usadas para crear las directrices para la misión de la iglesia fuera de la Escritura. Los pastores son llamados a enfocarse en la Escritura como la única regla de carácter, prueba de la experiencia, autoridad reveladora autoritativa de las doctrinas, registro confiable de los actos de Dios en la historia. Ellos fueron llamados a escuchar a la comunidad de fe tal como fueron enlistados a la enseñanza apostólica Timoteo y Tito en el primer siglo. Y ellos son llamados para tratar la palabra de verdad correctamente (2 Tim 2:15). Ellos no deben avergonzarse de los elementos apologéticos en su ministerio.

Además de las diferentes funciones pastorales mencionadas en estas cartas, cuando nosotros describimos el rol del pastor en nuestras sociedades y en nuestro tiempo, parece ser pertinente incluir esta perspectiva de una vida ejemplar. Al mismo tiempo, puede decirnos que el desarrollo del carácter es tan importante como lo académico y tan importante la búsqueda de las habilidades prácticas. Consecuentemente, tendríamos que preguntar la cuestión difícil de cómo nuestras escuelas y seminarios y cómo nuestra curricula contribuyen tanto a una profunda confianza en la Palabra de Dios y en el desarrollo de un carácter cristiano. Es lamentable que en un gran número de lugares los estudiantes del seminario estén tan propensos a engañar, a quebrar las normas y a exhibir un estilo de vida denominado mundanal, tal como lo hacen otros estudiantes. Es lamentable que entre los pastores encontremos asuntos ilícitos, codicia, herejías, criticismo severo, división, etc. 
Los prerrequisitos para un ministerio exitoso de un pastór de éxito incluyen lo siguiente:

(1) Conversión y andar cercano con Dios. En Tito es asumido el haber nacido de nuevo (Tito 3:5). Los cristianos ya son salvos ( 2 Tim 1:9). Ellos se acuerdan del Señor (2 Tim 2:8). La oración es enfatizada en 1 Timoteo 2:1-3.

(2) Siendo un estudiante diligente de la Escritura y apoyando la doctrina sana. Timoteo sabe las Escrituras desde su niñez. ". . . las cuales te pueden hacer sabio para la salvación por la fe que es en Cristo Jesús. Toda la Escritura es inspirada por Dios, y útil para enseñar, para redargüir, para corregir, para instruir en justicia, a fin de que el hombre de Dios sea perfecto, enteramente preparado para toda buena obra" (2 Tim 3:15-17). Él debe sostener las palabras apostólicas (2 Tim 1:13-14) y debe manejar correctamente la palabra de verdad (2 $\operatorname{Tim} 2: 15)$.

(3) Viviendo una vida ejemplar. Ser un ejemplo es enfatizado dos veces en las Epístolas Pastorales (1 Tim 4:12; Tito 2:7) Hansen declara: “. . . el ministerio pastoral es una vida, no una tecnología” y “. . . como y por qué seguir a Jesús es un principio del ministerio pastoral, el principio abarcante que integra cada deber". 8

8 David Hansen, The Art of Pastoring: Ministry Without All the Answers (Downers Grove: InterVarsity, 1994), 10-11. 
(4) Comprendiendo el llamado de uno y actuando de acuerdo con él. 2 Timoteo 1:9 habla acerca del llamado de Dios. Sin embargo, el texto parece referirse al llamado general de salvación. Pero en el versículo 6 Pablo menciona "el don que está en ti mediante la imposición de mis manos". Una frase similar se encuentra en 1 Timoteo 4:13.

(5) Comprendiendo el carácter y la misión de la iglesia de Dios. La iglesia es la iglesia de Dios (1 Tim 3:5). Hay fronteras de modo que debe ser mantenida una distinción entre aquellas que están dentro de la iglesia y aquellas que no lo están (1 Tim 3:7). La iglesia es "la casa de Dios ... la columna que sostiene la verdad” ( 1 Tim 3:15). Los miembros de iglesia deben asistirse los unos a los otros de manera que no sean una carga para la iglesia (1 Timoteo 5:16). "Si alguna vez fuimos culpables, como iglesia, de hacer hincapié en el adventismo a expensas de una orientación a la gracia y el amor a Cristo, ahora no debemos caer en la otra zanja de levantar una generación de adventistas sin ningún compromiso al rol del adventismo dado por Dios", escribe Jere Patzer. ${ }^{9}$

(6) Entusiasmo, pasión y compasión: Estas expresiones no ocurren en las epístolas Pastorales, sin embargo, el concepto parece estar presente. Por ejemplo, "predica la Palabra; estando preparado a tiempo y fuera de tiempo; redarguyendo, corrigiendo y exhortando -con gran paciencia e instrucción cuidadosa”

${ }^{9}$ Jere D. Patzer, The Road Ahead: A Vision for Spiritual Leadership in the 21st Century (Nampa, Idaho: Pacific Press Publishing Association, 2003), 25. 
(2 Tim 4:2). Ellos pelean la buena batalla de la fe (1 Tim 6:12; 2 Tim 4:7-8) y actúan con mansedumbre y comprensión (2 Tim 2:15; 1 Tim 5:1).

(7) Dispuestos a sufrir. Pablo habla de la disposición a sufrir (1:8) y la resistencia a las dificultades (2:3; 3:11-12; 4:5). Patzer pregunta: "pero, ¿podría la mayoría de nuestros esfuerzos estar yendo a rascar nuestras propias espaldas? No hay riesgo, no hay dolor, todo el mundo se siente bien, feliz y contento . . y envía más mensajes por correo electrónico". ${ }^{10}$ Irwin A. Busenitz nota que "Hoy en día algunos pueden considerar erróneamente el liderazgo cristiano únicamente como una posición de estatus, honor y prestigio... En los días de Pablo el oficio de anciano a menudo implicaba una considerable dificultad, peligro, el ridículo y el rechazo". ${ }^{11}$ No siempre es fácil ser un líder. Pero aún hoy día, en algunos países, el precio por servir a Dios en esta función puede ser la persecución y la muerte.

(8) Orientados hacia la meta. El evangelio debe pasarse a la siguiente generación (2 Tim 2:2). A los miembros de iglesia debe enseñárseles "a estar ocupados en buenas obras para los casos de necesidad, para que no sean sin fruto" (Tito $3: 14$ ), sino ser de ayuda a otros (3:8). ${ }^{12}$

${ }^{10}$ Ibíd., 95.

${ }^{11}$ Irvin A. Busenitz, "Training for Pastoral Ministry", in Rediscovering Pastoral Ministry: Shaping Contemporary Ministry with Biblical Mandates, ed. by John MacArthur, Jr. (Dallas: Word Publishing 1995), 120.

${ }^{12}$ Ver también, Tito 2:14. 


\section{El rol del pastor}

\section{Las funciones pastorales}

Las funciones pastorales encontradas en las Epístolas Pastorales pueden abarcar las siguientes, aunque debe reconocerse que algunas se sobreponen entre ellas:

(1) Enseñar: Enseñar ocurre frecuentemente en las Epístolas Pastorales y significa el acto de enseñar (1 Tim 4:11; 2 Tim 2:24) ${ }^{13}$ o el contenido, es decir, la buena enseñanza o la doctrina. Tito es llamado a "hablar las cosas que están de acuerdo con la sana doctrina (Tito 2:1). El llamado a usar y manejar correctamente la palabra de verdad (2 Tim 2:15) puede referirse a enseñar así como a predicar. En nuestro contexto de hoy enseñar podría -entre otros incluir las actividades de la Escuela Sabática, los estudios de grupos pequeños, la conducción de seminarios, y el estar involucrados en eventos de entrenamiento en la iglesia.

(2) Predicación. La predicación y la enseñanza pueden sobreponerse en cierta medida (2 Tim 4:2). Probablemente, aquí también podríamos incluir la lectura pública de la Escritura. En nuestro contexto la pre-

${ }^{13}$ Para una discusión sobre enseñanza ver, Lawrence O. Richards and Clyde Hoeldtke, A Theology of Church Leadership (Grand Rapids: Zondervan Publishing House, 1981), 126-135, and Thomas C. Oden, Pastoral Theology: Essentials of Ministry (San Francisco: Harper \& Row, 1983), 141-152. 
dicación se refiere a la proclamación del evangelio de un modo tal que la gente quede tocada y sea alcanzada. Incluye la preparación de sermones, el acto mismo de la predicación, la dirección en la adoración y la planificación de "los sermones para el año". ${ }^{14}$

(3) Cuidado pastoral. Haciendo recordar, encargando y advirtiendo a los miembros de iglesia (2 Tim 2:14), corrigiendo con mansedumbre ( 2 Tim 2:25), redarguyendo, exhortando y reprendiéndoles (2 Tim 4:2), así como urgiéndoles y animándoles (1 Tim 5:1-2; 6:2; Tito 2:6) puede ser parte de lo que llamaríamos cuidado pastoral. En nuestro contexto el cuidado pastoral podría comprender aconsejamiento, visitación a los miembros de iglesia y cuidando de la vida social de la iglesia.

(4) Administración y liderazgo. Esto puede incluir la elección de ancianos (Tito 1:5), el rechazo de las especulaciones necias e ignorantes que producen pleitos (2 Tim 2:23), silenciando y rechazando con severidad a los herejes (Tito 1:11, 13). Mandando (1 Tim $4: 11 ; 6: 17)$ y rehusando añadir algo en un lista específica (1 Tim 5:11) puede indicar el lado administrativo del ministerio. En nuestro contexto también podría significar conducir y guiar a la iglesia, soñar y realizar una visión, estar involucrado en planificación, motivando, comunicando, financiando y evaluando los resultados. ${ }^{15}$ Incluye tratar con jun-

\footnotetext{
${ }^{14}$ Swanson, 5 .

${ }^{15}$ Cf., Patzer, 53-56.
} 
tas, comunicándose con la iglesia y, especialmente, ayudando a la iglesia a servir a Dios, a los hermanos $\mathrm{y}$ hermanas, $\mathrm{y}$ a otros.

(5) Evangelizando. Las cartas Pastorales saben acerca del trabajo del evangelista (2 Tim 4:5). El evangelismo involucra encargar el mensaje de la iglesia "a hombres fieles que también serán capaces de enseñar a otros" (2 Tim 2:2). Hay una cadena de testigos que comienzan con Pablo. Él ha pasado el evangelio a Timoteo y Tito, quienes, a su vez, son encargados de pasarlo a otros que también enseñarán a otros. De esta manera, el evangelio nos ha llegado y se nos pide pasarlo, incluso si esto resulta difícil. Hoy día el evangelismo incluye la proclamación pública y privada del evangelio. El evangelismo es realizado también por los miembros de iglesia quiene necesitan ser entrenados y equipados por el pastor.

(6) Modelando. El modelar ya ha sido tratado arriba. Hemos sugerido que el pastor debe ser un ejemplo influenciando y motivando a los miembros de la iglesia y otras personas. En su libro sobre liderazgo L. O. Richards y C. Hoeldtke dedican un capítulo entero al modelaje. ${ }^{16}$ Ellos dicen que el método del líder consiste en modelar y enseñar. Indicando que la calificación de los líderes se encuentra en la Escritura, ellos concluyen: “. . . el requisito básico para los líderes espirituales no tiene nada que ver con las habilidades o la formación o, incluso, con la posesión de do-

${ }^{16}$ Ver, Richards, 114-124. 
nes particulares. El requisito básico para los líderes espirituales es que sean las demostraciones vivas de la realidad de todo lo que enseñan!" ${ }^{17}$ Modelar puede ser poderoso, bajo las siguientes condiciones:

1. Es necesario que haya contacto frecuente y a largo plazo con el modelo(s).

2. Es necesario que haya una relación cálida y amorosa con el modelo(s).

3. Es necesario que haya exposición a los estados internos del modelo(s).

4. El modelo(s) debe ser observado en una variedad de entornos y situaciones de vida.

5. El modelo(s) debe exhibir coherencia y claridad en comportamientos, valores, etc.

6. Es necesario que haya una correspondencia entre el comportamiento del modelo(s) y la creencia(s) (estándares ideales) de la comunidad.

7. Es necesario que haya conceptualmente una explicación del estilo de vida del modelo(s), con instrucciones que acompañen las experiencias compartidas. ${ }^{18}$

${ }^{17}$ Richards, 117.

${ }^{18}$ Lawrence O. Richards, A Theology of Christian Education (Grand Rapids: Zondervan Publishing House, 1975), 84. 
Aunque otras funciones del pastor podrían ser enlistadas, encontradas en otros lugares del Nuevo Testamento, estas seis parecen ser las mayores. Ellas también comprenden muchas otras. En un estudio hecho en la Unión Checoeslovakiana se investigó cinco de las mayores funciones pastorales, a saber predicación, administración, cuidado pastoral, enseñanza y evangelismo. ${ }^{19}$ Otros han enlistado otras y han añadido más funciones. ${ }^{20}$

\section{El pastor y la iglesia}

Ya hemos señalado el hecho de que el pastor necesita comprender el carácter de la misión de la iglesia.

\footnotetext{
${ }^{19}$ Ver, Swanson, 5
}

${ }^{20}$ John Roades, Success Secrets for Pastors (Silver Spring: The Ministerial Association, n.d.), 3-4, habla de esto (1) el pastor como un administrador, (2) el pastor como un evangelista, (3) el pastor como un predicador y sacerdote, (4) el pastor como un pastor, (5) el pastor como un promotor, y (6) el pastor como un incentivador de las relaciones públicas. En cierta medida, este libro es decepcionante porque se enfoca en cuanto a detalles técnicos. E.g., en vez de discutir lo que es la predicación y cómo funciona, el libro discute como operar sistemas e ítems similares. Oden divide su libro en cinco partes: (1) Llegando a ser un ministro, (2) El oficio pastoral, (3) Qué hace el clérigo y por qué, (4) Consejo pastoral, y (5) Crisis ministerial. Su tercer capítulo está subdividido en otras cinco partes que tratan sobre el pastor y la adoración comunitaria, bautismo y eucaristía, predicación, enseñanza, y equipamiento de los laicos para el ministerio. Paul Stevens and Phil Collins, The Equipping Pastor: A System Approach to Congregational Leadership (Bethesda: The Alban Institute, 1996), iii-v, tratan con (1) Uniendo tu propia iglesia, (2) Cultivando independencia, (3) Liderando el proceso, (4) Coincidiendo los estilos de liderazgo, (5) Cuidando los subsistemas, (6) Discerniendo el cuerpo, (7) Covirtiéndose en un líder cristiano, y (8) Libertando a la laicidad para la misión. Paul Cedar, en "el rol singular del pastor" ["The Unique Role of the Pastor"], 5-6, adopta otra perspectiva. Las subdivisiones de su capítulo son: "A renaissance Calling", "Entrance into People's Private Lives", "Public Proclamation to Those We Love", "Spiritual Counseling", "Vision Casting", "A Sacramental Presence", and "Birds Eye View of God's Grace”. 
El ministerio pastoral no es independiente de la iglesia. iTodo lo contrario! Si no hubiera iglesia, no se necesitarían pastores. Hablando estrictamente, una discusión sobre el ministerio pastoral es parte de la eclesiología. Consecuentemente, a fin de comprender el rol pastoral uno debe de comprender también el propósito de la iglesia. "La filosofía bíblica del ministerio debe estar enraizada en la eclesiología bíblica". ${ }^{21}$ Esta relación es evidente en 1 Timoteo 3:14-15: "Esto te escribo para que sepas cómo uno debe conducirse en la casa de Dios, la cual es la iglesia del Dios viviente, columna y baluarte de la verdad".

La iglesia es la casa de Dios. Existe una estrecha relación entre Dios y la iglesia. El Señor guía y apoya a la verdad. La iglesia honra y adora a Dios. La iglesia es la columna y baluarte de la verdad. La iglesia ha recibido el mensaje de Dios. Ha recibido la Palabra inspirada de Dios, los testigos apostólicos y la enseñanza, la verdad. La iglesia guarda este mensaje y lo proclama. 2 Timoteo 2:18 habla acerca de "hombres que se desviaron de la verdad, diciendo que la resurrección ya se efectuó, y ellos trastornan la fe de algunos". Obviamente esta verdad referida en las Epístolas Pastorales no es una idea nebulosa, sino tiene que ver con doctrinas cristianas tangibles. Por ejemplo, negando que la resurrección futura de la humanidad significa haberse apartado de la verdad. La iglesia no puede tolerar tales ideas erróneas. A. Montoya declara: La iglesia es una comunidad adoradora, una comunidad

${ }^{21}$ Alex D. Montoya, “Approaching Pastoral Ministry Scripturally”, in Rediscovering Pastoral Ministry: Shaping Contemporary Ministry with Biblical Mandates, ed. by John MacArthur, Jr. (Dallas: Word Publishing 1995), 68. 
testificadora y una comunidad trabajadora. En otras palabras, la iglesia está para exaltar al Señor, para evangelizar al mundo y para edificar a su feligresía”. ${ }^{22}$ Por lo tanto, "el rol del liderazgo pastoral ... es proveer guía, cuidado y vigilancia para la iglesia de modo que cumpla los mandatos ordenados por Cristo de evangelizar al mundo entero, creciendo en la semejanza de Cristo y existiendo para la exaltación y adoración de Dios". ${ }^{23}$

Además, la iglesia del Nuevo Testamento no está limitada a congregaciones aisladas. Mientras el Nuevo Testamento llama a las congregaciones locales iglesias, el también mantiene el concepto de la iglesia como una entidad universal. ${ }^{24}$ En 2 Timoteo 3:15 la iglesia no parece estar limitada a la iglesia en Éfeso, donde Timoteo sirvió. Otro concepto que los pastores necesitan tener en mente es la teología del remanente. Patzer sugiere que el ministerio personal debe considerar la teología (el mensaje), la misión, y la organización de la Iglesia Adventista del Séptimo Día. Los tres están estrechamente vinculados. Los pastores no pueden descartar uno de ellos sin causar daño a la iglesia, a la gente y a ellos mismos. Él escribe: "Yo creo que Dios levantó nuestra iglesia profética inspirando su teología, la cual guía su misión mediante su organización ... Todos estos elementos están intrínsecamente vinculados. Los tres son ordenados divinamente. Los tres son profundamente significativos". ${ }^{25}$

${ }^{22}$ Montoya, 68.

${ }^{23}$ Ibíd., 77.

${ }^{24}$ Ver, la iglesia en Éfeso contrastando la iglesia de Colosas. Mientras en Apo 2-3 son dirigidas a congregaciones individuales, Apo 12 describe a la iglesia universal.

${ }^{25}$ Patzer, 14. 
Los pastores que trabajan para la iglesia adventista deben comprender su carácter y no pueden ser negligentes con su mensaje y misión. Ellos deben servir dentro de estos límites establecidos por el carácter, mensaje y la misión de la iglesia. Ellos son urgidos a respetar y apoyar la iglesia. Ellos son los representantes de la Iglesia Adventista del Séptimo Día mundial. Su ordenación no está limitada a un distrito o país. Por lo tanto, ellos son desafiados de permanecer alejados de cualquier forma de congregacionalismo, provincialismo y nacionalismo. Servimos a una iglesia mundial. Debemos aprender a dibujar juntos en vez de edificar paredes de separación y enfatizar nuestras idiosincrasias. Por otro lado, nuestro entendimiento de la Iglesia Adventista del Séptimo Día, como el remanente visible, debe guiar nuestras relaciones con las otras iglesias. Aunque aquí y allá podría ser necesario señalar problemas en la iglesia, en humildad y, no públicamente. En un número del New York Times, una de las revistas más vendidas, un pastor adventista fue entrevistado:

"Como un excavador apasionado de sitios antiguos y pastor adventista del séptimo día ordenado, Doug parecía encarnar todas las tensiones entre la ciencia y la religión, entre la historia y la fe... Cuando nos sentamos en un banco, le pregunté cómo reconciliaba él este trabajo como un arqueólogo y sus creencias. 'Creo que he llegado a un acuerdo personalmente con la Biblia, un libro que es precioso para mí', dijo, 'de modo que yo no tengo que encerrarme en cada historia como un hecho factual. Mi propio sentido sobre la Escritura es que yo creo que hubo algún tipo de actividad 
divina detrás de la Biblia, pero no asumo que cada detalle de la historia es verdadera. No puede serlo. Pues yo no creo que los detalles sean importantes. Creo que las lecciones son importantes. ... No soy dependiente de factibilidad en todo. Yo puedo mirar hacia atrás y decir: Bueno, esto no sucedió de esa manera. De modo que no hubieron dos millones de personas en el Éxodo. Pero todavía tengo la sensación de que, histórica y arqueológicamente, podemos ver los elementos más grandes de la historia .... Crecí en una tradición en la que la tierra era sólo de seis mil años de antigüedad, pero yo estaba trabajando en un sitio que data alrededor de 250.000 años de antigüedad. .."”. ${ }^{26}$

Semejante declaración puede causar daño. Aunque la lucha del individuo pueda ser entendible, la equidad requeriría o bien abstenerse de hacer tal declaración en público, la cual contradice lo que la iglesia representa o, también, retirarse del ministerio pastoral. Los pastores que trabajan para esta iglesia deben comprender su naturaleza y propósito, respetarla y apoyarla.

\section{Desafíos y conflictos de rol}

Los pastores en su ministerio han tenido toda clase de desafíos y conflictos. Un problema es la multiplicidad

${ }^{26}$ Bruce Feiler, Walking the Bible: A Journey by Land through the Five Books of Moses (New York: HarperCollins Publishers, 2002), 404-405. 
de roles que un pastor tiene que realizar y la dificultad de hacer justicia con todos ellos, funcionando simultáneamente con una esposa, un pariente, el niño de uno de los padres, un pastor, un supervisor, un empleado o alumno, solo por nombrar algunos de ellos aquí. Por otro lado, hay peligros y desafíos para el pastor que están relacionados con sus funciones pastorales.

(1) La presión del tiempo. La presión de tiempo que los pastores tienen que soportar, al tratar de hacer justicia a las funciones pastorales, puede ser muy estresante. El estudio de Swanson, hecho con los pastores en la Unión Checoeslovaca, demostró que "el pastor promedio trabajaba 65 horas a la semana, y algunos apretando llegaban hasta unas $85 \% \cdot{ }^{27}$ Los pastores necesitan planificar su tiempo diligentemente, priorizando, delegando y evaluando. ${ }^{28}$

(2) Ministerio desequilibrado. Existe el peligro de un ministerio desequilibrado. Los pastores pueden preferir ciertas funciones sobre otras, dejando a un lado las otras. Tienen sus caballos como hobby, funciones que son realizadas más fácilmente y que no requieren de mucho esfuerzo. Algunos emplean mucho tiempo en la preparación de sermones. Otros dedican mucho tiempo a la planificación del servicio de adoración. A menudo sufre la enseñanza, especialmente la formación sistemática de los miembros de la iglesia. A veces, la evangelización pública es

${ }^{27}$ Swanson, 5 .

${ }_{28}$ Ver Patzer, 67-69, donde él trata con la administración del tiempo, 5-8. 
despreciada. Muchos de estos problemas se pueden atribuir a la falta de visión y planificación por parte del pastor.

(3) Ignorando el contexto de la Iglesia Adventista del Séptimo Día. Existe el peligro de ignorar el contexto de la Iglesia Adventista del Séptimo Día, a saber, su mensaje y la misión. Algunos pastores vienen con sus propias interpretaciones extrañas. Otros defienden ideas que se encuentran en los ministerios independientes, otras iglesias, la ciencia y, en otros lugares, tales como la evolución teísta, la teología del proceso, la teoría de la influencia moral, la justificación universal, la nueva teología del pacto y los nuevos escenarios del tiempo del fin.

(4) La falta de éxito y sus consecuencias. En algunas partes del mundo los pastores sufren de una falta de éxito, lo cual puede conducir al desgaste. Pueden llegar a ser extremadamente críticos, el probar las últimas modas o mantener el status quo, por estar sirviendo sin pasión y entusiasmo y trabajando lo menos posible. Con frecuencia la falta de pastores de éxito se debe a la falta de crítica y el trabajo sin mucha reflexión, al aplicar las últimas tendencias en el cristianismo como elementos del movimiento crecimiento de la iglesia, modelos para la creación de mega-iglesias, métodos de liderazgo derivados de modelos de negocio, elementos carismáticos y los modelos de renovación del culto.

(5) La falta de modelación. Otro peligro es la noción de que todos son iguales, que el pastor es sólo uno de la multitud, y que, por tanto, el modelaje no es necesario. El pastor y su familia rechazan la idea de vivir una vida ejemplar. 
(6) Una falta de interés en asuntos teológicos y los estudios bíblicos. Olson advierte: "A veces la corrección doctrinal y teológica ha importado demasiado. Pero en todo caso, en nuestros días el péndulo ha oscilado hacia el extremo opuesto, que muchos cristianos saben poco o nada acerca de las doctrinas cristianas o cómo o por qué se han desarrollado. El cristianismo está en peligro de convertirse en poco más que una religión popular de culto terapéutico y sentimientos individuales". ${ }^{29}$ Hoy día muchos pastores se centran casi exclusivamente en la teología práctica y no están interesados en el estudio de temas teológicos y bíblicos. Se crea una dicotomía entre la vida, entre lo que se considera importante y la doctrina, así como estudios bíblicos, que son vistos como nada práctico. "Soy muy consciente", afirma Marguerite Shuster, "que estoy nadando contra una marea poderosa cuando abogo por un renacimiento de la predicación doctrinal . . . las respuestas van desde la ansiedad, al terror, a la fuga". ${ }^{30}$ Hay miembros de la iglesia que no hacen más preguntas sobre cuestiones bíblicas a sus pastores, porque afirman que sus pastores no saben bien teología ni están dispuestos a hacer una investigación, a fin de llegar a una respuesta. Si decimos que la Biblia es fundamental para lo que creemos, entonces eso necesita la debida atención. "Tan práctico como la

${ }^{29}$ Roger E. Olson, The Story of Christian Theology: Twenty Centuries of Tradition \& Reform (Downers Grove: InterVarsity Press, 1999), 17.

30 "Preaching Christian Doctrine: Derek Morris interviews Margarite Shuster", Ministry, January 2002, 10. 
vida misma", escribe Roy Adams, "la [teología] es lo que nos impide ser engañados o manipulados por los descarriados e inescrupulosos. Ella forma la roca firme que es la base sobre la cual anclamos todo lo demás. Sin ese fundamento estamos totalmente a la deriva" ${ }^{31} \mathrm{Es}$, por ejemplo, deseable que un pastor sea eficaz en los ministerios de grupos pequeños, pero esto no le hace a él un pastor adventista. Es el mensaje el que hace toda la diferencia, no las técnicas y habilidades. ${ }^{32}$ Ambos necesitan ir de la mano, siendo el mensaje el que tiene la prioridad y por encima de las habilidades. Peter Schmiechen enumera varias razones por las cuales el pensamiento teológico está descuidado por muchos, ${ }^{33}$ a las que hemos añadido algunos más: el individualismo, el funcionalismo, el deseo de ser autónomo, el consumismo, un enfoque sociológico, el pluralismo, el relativismo, la emotividad, el elitismo y la apatía.

${ }^{31}$ Adams, "En un tiempo de confusión”, 20. Él continua: “¿'Todo lo que necesitamos es a Jesús’? ¿Qué es Jesús? ¿Quién es Jesús? Y ¿̇por qué le necesitamos a él, y no a Buda o a Platón o a Mahoma o a cualquier otro? Sin la teología, esa afirmación, o tanto como nosotros podamos agregar o estar de acuerdo con él en su cara, no tendría absolutamente ningún contenido o significado. El nombre Jesús, como una referencia a una persona que vivió hace 2.000 años en Palestina, solo se puede apreciar correctamente en un contexto teológico. Sin ese contexto, es vacío y carente de cualquier significado.

${ }^{32}$ Montoya, 72, declara, "Sin embargo al introducir programas innovadores en favor del cambio y emoción sin concentrarse realmente en la enseñanza de la Palabra de Dios es como cambiar los platos para el almuerzo sin preocuparse por el correcto alimento que se sirve en esos platos".

${ }_{33}$ Peter Schmiechen, Christ the Reconciler: A Theology for Opposites, Differences, and Enemies (Grand Rapids: Wm. B. Eerdmans Publishing Company, 1996). 
El pensamiento teológico es considerado por algunos como demasiado difícil, demasiado aburrido y consumidor de demasiado tiempo. Por lo tanto, tenemos que pedir a los pastores el involucrarse más en los estudios teológicos, a fin de aprender a disfrutar de la belleza del mensaje bíblico. Los pastores necesitan tomar tiempo para estudiar a fin de presentar - cuando predican - una "comida saludable" y no sólo una forma espléndida sin mucho contenido. Ellos necesitan crecer personalmente en su comprensión de Dios, su voluntad y su plan de salvación. En gran medida, los pastores son responsables del clima en sus iglesias. Esto incluye la comprensión teológica y el amor por la Palabra de Dios.

(7) Dudas sobre la Escritura. Las dudas acerca de la Escritura pueden ser causadas por una variedad de razones, entre ellas las crisis en la vida de uno y el estar expuestos a la teología crítica. En algunos círculos se rechazan los conceptos de la revelación y la inspiración divina. La influencia sobrenatural no solo en la Escritura, sino sobre la vida en la Tierra es rechazada. La idea de que la Escritura es estrictamente acondicionada culturalmente no contribuye a la apreciación de la Escritura. Lo mismo ocurre si se acepta el postmodernismo. Las doctrinas que están siendo cuestionadas son la creación, la salvación, la Trinidad, el sábado, el santuario y el remanente. Martín Lutero dijo: "Un obispo, que descuida la Palabra de Dios es un lobo y un apóstol de Satanás, aunque fuera santo". ${ }^{34}$

${ }^{34}$ Martin Luther, WA 8, 29, citado en Bernhard Bonkhoff, "Das Wort der Kirche”, Informationsbrief, Feb 2003, No. 216, 5 . 


\section{Resumen}

Las funciones pastorales más importantes son enseñanza, predicación, cuidado pastoral, administración y liderazgo, evangelismo y modelar. Ellas deben ser usadas de un modo equilibrado. La enseñanza es tan importante como la predicación. La modelación es un ingrediente esencial. Los estudios bíblicos y la teología sistemática son tan importantes como cursos prácticos. Nuestra eclesiología debe informar y dar forma al ministerio pastoral. Entonces, los desarrollos extraños deben ser evitados o corregidos. Los conflictos y desafíos en el ministerio pastoral deben ser muy difíciles, especialmente cuando ellos están relacionados con el fundamento de nuestro mensaje, el cual es la Escritura. A fin de prevenir estos problemas y desafíos o ayudar a los pastores a estar abrumados con ellos; son necesarios un entrenamiento básico sólido, supervisión y educación continua.

\section{La formación teológica del pastor}

Habiendo discutido el rol de pastor, debemos ahora tornarnos a quienes los educan a ellos, los profesores de teología y a su mandato. I. Busenitz sugiere:

“... El entrenamiento para el ministerio pastoral no puede ser impulsado por el mercado; este debe ser impulsado por la Biblia. La formación pastoral no puede rendirse a los caprichos de los asientos de la feligresía, ni ceder a la última metodología de crecimiento de la iglesia. Por el contrario, una educación que refleja los mandatos bíblicos para la iglesia y su 
liderazgo debe dominar la formación pastoral.... El mandato de los seminarios y líderes de la iglesia es enseñar primero el qué y el por qué de la dirección de la iglesia antes del cómo. . . . En concreto, la formación para el ministerio exige la búsqueda de, por lo menos, las tres fases de la formación notadas en la exhortación de Pablo a Timoteo (I Tim. 4: 12-16): buen carácter (lo que un hombre debe ser), el conocimiento bíblico (lo que un hombre debe saber), y habilidades para el ministerio (lo que un hombre debe ser capaz de hacer)". ${ }^{35}$

Nosotros deseamos hacer las siguientes sugerencias:

(1) El fundamento de la Escritura: Debido a que las Escrituras del Antiguo Testamento y la enseñanza apostólica, tal como son preservadas en el Nuevo Testamento, forman el fundamento de todo ministerio, los maestros deben infundir en sus alumnos confianza en la Escritura como la Palabra de Dios. Aunque se levanten preguntas relevantes y se debatan los problemas pertinentes, esto se hace desde la perspectiva de la fe evitando usar las herramientas de los métodos críticos que minan la fe y cuestionan la confianza y la autoridad de la Escritura. De lo contrario, estamos en peligro de perder nuestro mensaje y, de este modo, nuestra identidad.

(2) Los profesores como modelos. Los estudiantes de teología necesitan modelos. El comportamiento y el estilo de vida de los profesores deberían ani-

${ }^{35}$ Busenitz, 117-119. 
mar a los estudiantes a convertirse en un ministro fiel, dedicado, entusiasta y a ser ejemplo para sus alumnos y estos, a su vez serlo para sus miembros de la iglesia. Sin embargo, si los profesores no van a la iglesia el sábado, evitan las actividades de la Escuela Sabática y de la iglesia, se burlan de los miembros de la iglesia, siempre llegan tarde a la clase, no toman la enseñanza en serio y no dan lo mejor, enseñan a sus estudiantes para percibir el ministerio como un puesto de trabajo y no como un llamado, a conformarse con medidas mediocres, y a no ser serios en el ministerio. La falta de estilo de vida ejemplar de un maestro no solo afectará a los estudiantes sino, demasiado tarde o temprano, también a las iglesias locales.

(3) Formando caracteres divinos. Los profesores de teología no pueden enseñar el conocimiento de contenidos y habilidades. De alguna manera deben conformar el carácter de sus alumnos. Dado que en las cartas pastorales las calificaciones y cualidades del ministerio se pronuncian con más fuerza que sus funciones; los maestros se llaman así porque de una manera u otra deben procurar ayudar a los estudiantes a crecer en su relación con el Señor y madurar en sus caracteres.

(4) El conocimiento bíblico. "Del estar bíblicamente informado y teológicamente en lo correcto, debería derivar su motivación, primero y por sobre todo, emanado de su anhelo de conocer a Dios íntimamente (Fil 3: 8-10)". ${ }^{36}$ Lejos de provenir del deseo

${ }^{36}$ Busenitz, 123 . 
de ser reconocido por los eruditos seculares y recibir la etiqueta de "científica". J. I. Packer dice: "No puede haber salud espiritual sin conocimiento doctrinal; pero no es menos cierto que no puede haber salud espiritual con él, si se busca con el propósito equivocado y valorado por un criterio erróneo". ${ }^{37}$ El conocimiento bíblico incluye el conocimiento de los idiomas bíblicos, el proceso de hacer la exégesis y la teología bíblica, histórica y sistemática. Los profesores entrenan a sus estudiantes en estas áreas. ${ }^{38}$ Si miramos la currícula de los programas académicos diseñados para preparar pastores adventistas, notamos la tendencia a añadir clases de teología aplicada y a desechar clases de tratan los asuntos teológicos, Antiguo Testamento y los estudios de Nuevo Testamento, así como los idiomas bíblicos. ${ }^{39}$ Este en un desarrollo nada saludable.

${ }^{37}$ J. I. Packer, Knowing God (Downers Grove: InterVarsity Press, 1993), 22-23.

${ }^{38}$ Hansen, 9-10, relata su propia experiencia cuando él comenzó trabajando como pastor: "Cuando empecé el ministerio pastoral, yo tenía un montón de esos libros llamados cómo-hacer, el ministerio-pastoral. . . Ellos no me ayudaron. Los autores suponen mucho. Se suponía que yo sabía lo que era mi objetivo. Se suponía que sabía por qué debía estar haciendo las cosas que se me había enseñado. Pero yo no sabía lo que yo era, o quién era yo, o por qué se suponía que debía estar haciendo las cosas que se suponía que tenía que estar haciendo. ... Así que dejé de leer los libros sobre procedimientos. En vez eso leí teología, estudios bíblicos e historia de la iglesia. ... Estos libros de las disciplinas clásicas de teología no me enseñaron cómo hacer el ministerio pastoral, pero ellos me ayudaron enormemente en mis tareas regulares".

${ }^{39}$ Aquí aparece un bosquejo del programa de Maestría en Divinidades de tres seminarios norteamericanos no adventistas, dos en la tradición liberal y uno con una perspectiva conservadora. En el Programa de Maestría 
(5) Habilidades pastorales. Las habilidades pastorales incluyen "dirigir con convicción, enseñar con autoridad, predicar [y evangelizar] con pasión $\mathrm{y}$, pastorear con cuidado. ${ }^{40}$ Pero las habilidades $\mathrm{y}$ funciones pastorales no pueden se practicadas separadamente. Cuando nos preparamos para predicar surgen dos preguntas, llamadas el "qué" y el "cómo". La pregunta del "como" es respondida por la homilética, donde hay que tratar con ciertos métodos. La cuestión del "qué" nos señala la Escritura, la exégesis y la teología. Lo mismo es cierto para la enseñanza. Sin embargo, es insatis-

en Divinidades, del Seminario Teológico de Chicago, se requieren dos cursos de Antiguo Testamento, dos de Nuevo Testamento, tres de teología, dos de historia de la iglesia y nueve clases de teología aplicada, pero no hay clases de idiomas bíblicos. La declaración de la misión, del Seminario Teológico de Chicago, revela un énfasis en una agenda socio-política que incluye toda la agenda ecuménica. De los 24 cursos medianos necesarios para completar la Maestría en Divinidades de la Escuela de Teología de Harvard, al menos doce deben de ser llevados en la Escuela de Divinidades. El resto puede ser llevado en otras escuelas. De los doce cursos, tres deben de ser llevados en el área de "Escritura e Interpretación", seis en el área de "Cristianismo y Cultura", y tres en el de "Religiones del Mundo". No se requiere Idiomas y el estudio de la Escritura es bastante limitado. Por lo tanto, hay un fuerte énfasis en religiones comparadas y poca exigencia en la Escritura. El Seminario Teológico Providencia adopta otro planteamiento; su Maestría en Divinidades requiere 61 créditos por semestre. De los 61 créditos, 15 están dedicados a las lenguas, otros 15 a los estudios bíblicos y teológicos, seis a los de historia de la iglesia y 25 a la de teología aplicada. Sin embargo, el requisito previo para el programa de la Maestría en Divinidades es de 30 horas de Biblia y Teología. En su compromiso con la fe de los miembros, de la facultad del Seminario Teológico de la Providencia, afirman un alto concepto de la Escritura, la salvación a través de Jesús, la aceptación del relato de la creación, la importancia de la escatología y la responsabilidad de anunciar el Evangelio. Ver todo esto en los respectivos boletines.

${ }^{40}$ Busenitz, 128. 
factorio si un profesor de homilética por no tener nada qué decir acerca de la exégesis y la teología le deriva a su alumno a un colega. Es también insatisfactorio si los pastores saben cómo predicar, pero no saben qué decir. En consejería pastoral, la cuestión es si nosotros estamos informados y de acuerdo con la Escritura, o toman un enfoque que está principalmente y más que todo alineado con la sociología y la antropología. Es inconsistente afirmar sola Scriptura, estudiar la Escritura sobre cómo manejar ciertos problemas, y luego olvidarlo todo y más bien hacer lo que cree que está bien o le parece que es bonito. Debiéramos de ser reacios a deshacer, mediante acciones pastorales, lo que la Escritura claramente nos dice que hacer, y crear una dicotomía entre un enfoque pastoral y un enfoque teológico. La Escritura debe informar acerca del cuidado pastoral.

"La pérdida de pensamiento teológico en las bancas de la iglesia, así como en el púlpito, podría ser mejor explicado. . . por la manera en la cual la modernidad vuelve a enfocar nuestros intereses, desplazando a la moral por la terapéutica, lo divino por lo humano, la verdad por la intuición y la convicción por la técnica. Como resultado tenemos, no solo el humanismo secular en nuestra sociedad, sino también evangelismo secular". ${ }^{41}$

${ }^{41}$ David F. Wells, Losing Our Virtue (Grand Rapids: Wm. B. Eerdmans Publishing Company, 1998). 


\section{Conclusión}

Tal como es esencial la iglesia, lo es también el ministerio pastoral. Ambos se pertenecen y ambos se dan forma el uno al otro. En tanto que estamos agradecidos por el don precioso del ministerio, sentimos la necesidad de reflejarlo en él, apoyarlo y fortalecerlo, de tal modo que sea una constante bendición para la iglesia y la sociedad. 